\title{
Roles the CEO and the Top Management Team play in Shaping Corporate Strategy, Operations, and Culture.
}

\author{
Bing Liu \\ Research Associate, Project Manager 100031
}

\begin{abstract}
In recent years, with the continuous development and progress of e-commerce and Internet economy, the logistics industry has got the opportunity to develop and grow. With the rapid development of the logistics industry, there are also many problems in the aspects of logistics cost control, which not only lead to the decline of the economic benefits of the logistics industry to a certain extent, but also affect the logistics quality and customer service to a large extent. Packaging logistics technology has an important impact on logistics cost management. Reasonable research and development and improvement of 1ogistics cost technology can provide great help for logistics cost optimization. Targeted analysis and application of packaging logistics technology can significantly optimize logistics costs and promote the development of logistics industry and $\mathrm{e}-$-commerce.
\end{abstract}

Keywords: commodity packaging; Logistics technology; The logistics cost

DOI : $10.36012 /$ ems. v2i2. 2798

\section{Abstract and Introduction}

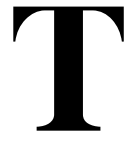

he global economy has created a new competitive landscape in which business events constantly change with a

high level of uncertainty. After the outbreak of the Covid-19 pandemic, the emerging complexity of such challenges faced by an organization requires the Chief Executive Officer (CEO) and other toplevel executives to acquire a broad knowledge of the firm's operations and the firm's external environments. Therefore, many organizations try to form a top management team (TMT) with the essential functional knowledge and industry expertise to manage the internal operations, select and implement the adaptive strategies, influence and shape the organizational cultural values, and carry out effective communications with all stakeholders and competitors.

In the year 2020, like the fall of the Berlin Wall or the collapse of Lehman Brothers, the coronavirus pandemic is a world - shattering event whose far - ranging and long - lasting consequences have just started. In meeting all the emerging challenges, leaders from the TMT within an organization are expected to adopt a competitive mindset in which mental agility, firm flexibility, speed, innovation, and globalized strategic thinking are highly valued (R. Duane Ireland \&. Michael A. Hitt, 2005). Through effective strategic leadership, an organization can be mobilized and exploit different growth opportunities for sustainable development.

This paper investigates the influence of the CEO and the TMT's leadership styles on organiza- 
tional performance. It looks into three aspects of their roles for the strategic leadership implementations, including shaping corporate strategy, exploiting and maintaining core competencies for business operation, and shaping the organizational culture; analyzes them in the global context, and provides recommendations for effective strategic leadership practices.

\section{Roles the CEO and the TMT Play}

\section{1 The Effects of Leadership Roles on the Organi- zational Performance}

Organizational performance transpires a highly regarded relationship between business strategy, leadership, and innovation (Hellriegel and Slocum, 2011, p. 291-297). The performance of an organization can be measured by the effectiveness of the TMT's leadership. CEOs influence organizational effectiveness mainly through the roles they play and the behaviors they display along the process (Quinn, 1988).

Transformational leadership and adaptability

In terms of the leadership style, many research findings assert that $\mathrm{CEO}$ and other top executives should adopt transformational leadership, which empowers people to exceed their previous levels of accomplishment, leading to positive organizational achievement beyond expectations, especially during critical times, such as financial crisis, energy shortage, geographic expansion and so on. Acting as a transformational leader, Alan $\mathrm{Mu}^{-}$ lally, the CEO of Ford Motor Company, adaptively accentuated the new organizational strategy of fewer products to produce sustainability improvement and service innovation; and managed to motivate the staff members through incentives, cultural inspiration, intellectual stimulation, and showing concern for the individual needs of the company's stakeholders; all such efforts helped move forward Ford to a new and improved business outlook despite the 2008 economic downtown.

According to an interview with Ronald Heifetz, founder of the Center for Public Leadership, Kennedy School of Harvard (2005), today's world has generated a level of interdependency that makes nearly all people at a local level feel less in control of their domains in their lives. The interconnected world of networks puts enormous pres- sure on people in high positions of authority to both prepare people for the adaptability they need in an interdependent world and at the same time regulate and manage the level of disturbance resulting from the uncertain environment. Hence the adaptability and the emotional intelligence to stay calm in the midst of ambiguity, to maintain poise in the midst of uncertainty, and to respond to the occurring changes with faith and creativity are crucial for the charismatic and successful leadership of the CEO and the TMT. In short, transformational leaders with a high level of adaptability could achieve the mutual benefits of the organizational tasks' accomplishment as well as the desired employees' commitment.

Task - and Relationship - oriented Behaviors of the CEO and the TMT.

Hart and Quinn (1993) proposed a general portfolio of the TMT's roles, including vision setter, motivator, analyzer, and taskmaster. Hart \& Quinn's research asserts that the four roles are closely linked with both the task - and relationship - oriented behaviors of CEOs which are all critical and contribute to the overall organizational performance. The functions of the vision setter, analyzer, and taskmaster are concerned with how the CEO and the TMT evaluate the proposed projects and make trade- off decisions and allocate resources; on the other hand, the role of motivator is directly correlated to employees' attitudes towards and attainment to the company.

This paper rates the two behavioral orientations of equal importance. To test the assumption, the author of this essay interviewed Mr. Haiting YAN, the CEO of Agricultural Bank of China (UK) Limited [https://de. wallmine. com/hkse/ 1609/officer/1792767/haiting-yan]. In the interview, Mr. Yan claimed that adhering to the parent bank's strategy of prudent risk management to create value. The London subsidiary shall focus on improving corporate value and customer service to differentiate itself from our competitors. The operational functions concentrate on wholesale banking, including corporate deposits, syndicated and bilateral loans, trade financing, and foreign $\mathrm{ex}^{-}$ change settlement transactions. He also addressed that the future success of this newly-established entity would much rely on the quality and the abili- 
ty of our employees to deliver unfaltering Service Excellence. The collective success depends mostly upon co-operation, trust, and respect between all employees at all levels. As the CEO, Mr. Yan stands that both of his task - and relational behaviors serve as crucial factors to the organizational performance, as task completion is a direct indicator to the business performance, whilst relationship - building would foster stronger employees' job satisfaction and high morale, facilitating the task completion process and resulting in the expected business performance.

To conclude, it is recommended that CEO and the TMT hone the skills of adaptability in their various roles to react in an effective manner, particularly in the shifting circumstances in the business environment. To achieve a better level of adaptability, managers, especially the TMT, should adopt an approach of flexibility facing fluctuating internal, market, and other external changes; adjust the behaviors in both task - setting \& monitoring, and employee motivation in line with the market evolvement and business development; keep open - minded and commit to learning always and reacting accordingly to any arising problems and challenges.

\section{2 Determining Strategic Direction and Shaping Or- ganizational Strategy}

According to M. A. Hitt et al. (2003), determining the strategic direction of a firm involves developing a long - term vision of the firm's strategic intent. A clear organizational strategy allows a company to focus its development efforts towards increasing its competitive advantage and forming a cultural glue fostering knowledge sharing and team collaboration. The effective leadership of the TMT, therefore, can substantiate the successful performance of the organization through their strategic planning and focus on resources optimization in a challenging environment to generate sound profitability and subsequently create the shareholder's value to a large extent.

Once the CEO and the entire TMT members have set the organizational strategy, all the employees should be empowered to devise the action plans to implement the strategy, and evaluate the business performance towards the ultimate accomplishment in accordance with the strategy; and re- vise the strategy from the valuable feedbacks and assessments. In this process, open communication among all organizational members to fully utilize everyone's skills in achieving the business goals is a key attribute to the success of a strategy and the success of leadership as well. As discussed in section 2. 1, Alan Mulally, CEO of Ford Motor Company, possessing high regard for the executive management and maintaining open communication, linked the whole organization to the pledge of "One Ford, One Tea [https://www. mainlandford. com/blog/the - way - forward/] m" and bolstered up the smooth implementation of the organizational strategy on sustainability improvement and service innovation.

In terms of the strategy implementation, this paper recommends the CEO and the TMT should facilitate and coordinate honest and timely communication among all the employees, foster more employee involvement and team cohesion, especially during the period of strategic organizational change, launch efficient training programs, adjust the KPIs, provide monetary and non - monetary incentives for employees' desired performance and attainment to the organization, etc.

Managing Changes in Organizational Strategy

As quoted from Charles Darwin, "It's not the strongest nor most intelligent of the species that survive; it is the one most adaptable to change. " For companies to survive and strive in today's competitive environment, they will need to change quickly and successfully. Meanwhile, according to the study of IBM Global Business Services (2008), in the fast - changing global economy and markets, most changes in strategic direction are difficult to design and implement as changing the vested mindsets, the attitudes of people, and the corporate culture are quite difficult to facilitate and manage; the technical support and other corresponding resources are not always optimally updated and rearranged, and the complexity of strategic change itself is challenging to predict and control.

One case was about General Electric (GE)'s CEO transition when GE had performed exceptionally well under Jack Welch's leadership. Whilst the shifting competitive landscape requires the newly appointed CEO, Jeffrey Immelt, to foster the stakeholders' commitment to a new vision and 
strategic direction while maintaining the previous, ongoing positive business performance. The challenging tasks for Immelt are about strategic reposition with reinforcement on industrial and consumer goods businesses and greater transparency in accounting practices. Besides, the previous profitability model focusing on cost reduction and acquisition could not help stop GE's suffering during Immelt's time. Therefore, he made several changes in the organization's strategy and managerial practices, including determining the company to invest in R\&D innovation for the development of an excellent engine for the small jet market; and developing a more independent board of directors to ensure transparency on all business practices. In taking this action, Immelt' $\mathrm{s}$ integrity and commitment to effective corporate governance were appraised by the management team. The organizational strategy shifts highlights enhancing the long - term shareholders' value of GE.

In view of the studies of global business and the GE's case above, this essay recommends that CEO and the TMT within an organization should possess a growth orientation as the realities of the competition in the global economy demand a corporate strategy focus on growth rather than downsizing and cost reductions. For instance, strategic approaches can be referred to in pursuit of growth for manufacturing comprising innovation, product development, structure decentralization, etc.

\section{3 Exploring and Maintaining Core Competencies for Business Operation}

Amongst the dynamic environment every organization is facing in today's business world, it is essential for an organization to consistently improving and maintaining its competitive advantage in the industry. As the resources and capabilities over the rivals, Core competencies relating to the organization's functional skills such as R\&D, manufacturing, finance, and marketing would propel the business operations in harvesting the value for stakeholders. The TMT associated with functional knowledge and industry expertise typically enables the leadership role models to develop and motivate the personnel, create a productive environment and obtain an outcome. Additionally, according to Hitt et al. , senior leaders providing coaching and mentoring to less-experienced personnel could ensure leadership succession.

In a study by Tara Duggan and Demand Media, roles of the CEO and the TMT in facilitating the business operation are classified into four major areas consisting of developing human capital, managing tasks, maintaining social responsibility, and presenting self - discipline. Human capital is a critical resource on which many core competencies are build and through which competitive advantages are exploited successfully. Viewing employees as a resource to be maximized rather than a cost to be minimized facilitates the success ${ }^{-}$ ful implementation of a firm's strategies and business operation (Nixon et al., 2001). Hence this essay recommends that the $\mathrm{CEO}$ and the TMT understand the cultural differences of employees and business practices across regions, and ideally, speak at least two to three languages to better manage the culturally diverse organization in the trend of globalization.

In terms of task management for business operations, leadership roles require the ability to solve problems, execute complex tasks, manage information, allocate resources, and monitor progress. By gaining expertise in a specific functional field and operational processes, the CEO would have a clear picture of the responsible task, which makes them more likely to optimize or innovate the process among the whole team under his/her leadership. Even if the CEO and the TMT were not directly engaged in dealing with some functional tasks, the strategic guidance and motivation from the TMT would facilitate the functional operations in progress from middle and frontline offices, thus reinforcing and developing the core competencies of the company. Concerning disciplinary working etiquette, the $\mathrm{CEO}$ and the TMT are responsible for setting the code of conduct and behave as role models to integrate discipline in every practice of the organization and impel the commitments in employees' work behaviors.

In terms of strengthening the core competencies, the CEO and the TMT are also recommended to enable the organization to develop and protect the intellectual capital and facilitate knowledge sharing among the involved parties. Knowledge acting as a source of competitive advantage would help the organization's business generate above- 
average financial returns.

\section{4 Shaping Organizational Culture}

Organizational culture serves as the glue that holds every member within an organization together, forms group identity, influences personal values and guides individual behaviors. According to Anne S. Tsui et. al (2006), organizational culture as shared social knowledge about the prevalent rules, norms, or values that shape the preferences or actions of the participants. The shared social experience serves to guide the behavior and actions of employees as well as decisions that are necessary for internal integration and critical for external adaptation. It is also found that the CEO's performance- building behaviors such as vision and strategic intent and institution behaviors lead to the creation of organizational processes and structural characteristics that strengthen the corporate cultures. Schein's (2004) study proposed that the TMT within an organization is the primary influence on the creation and development of organizational culture. In a way to bolster up the socialization of the established corporate culture, this essay suggests that the CEO and the TMT set up the rewarding system in line with the corporate cultural values, which can serve as an incentive and expedite employees' socialization process, thus mutually reinforcing the espoused cultural values as well.

Many venture - backed competitors jump in and fight for customers in the Chinese market. Taking Ofo as an example, as a previous unicorn tycoon running a bike-sharing business, Ofo used to subsidize services, pay for referrals, and in- crease the customer base, and yellow color roads were immersed everywhere. By mid-2017, Ofo had excellent service with massive consumer adoption, it was one of two market leaders, and it had partnered with Didi and Alibaba. But it somehow snatched defeat from the jaws of victory: it ran out of money, stayed independent, and broke up with Didi and Alibaba.

Every management team has weaknesses and gaps, Ofo's senior executives underestimated how long money wars can last in China and didn't preserve the capital so that the means are run out, and the company suffered harsh cash flows. It is investigated that the $\mathrm{CEO}$ of Ofo maintained an authoritative management style and rejected the business acquisition suggestions of capital tycoons. Evidently, no company can be the dominant leader of the industry forever, leaders being authoritative and only trusting ' his own ideals' could lead the organization to a future with great uncertainties.

Organizational cultures are continually evolving and reacting to shifts in the corporate and external environments. Given this dynamic nature, organizations must be viewed as a living construct needing continued support and attention. According to the survey (Figure 1) conducted by Peak Development Consulting, LLC., defining the vision for various stakeholders should be among the first steps a leader should take in his/her culture initiatives. Vision, like the word itself, is dynamic, not static, and must be renewed, adapted, and adjusted with the changing business environment (Bennis, p. 178).

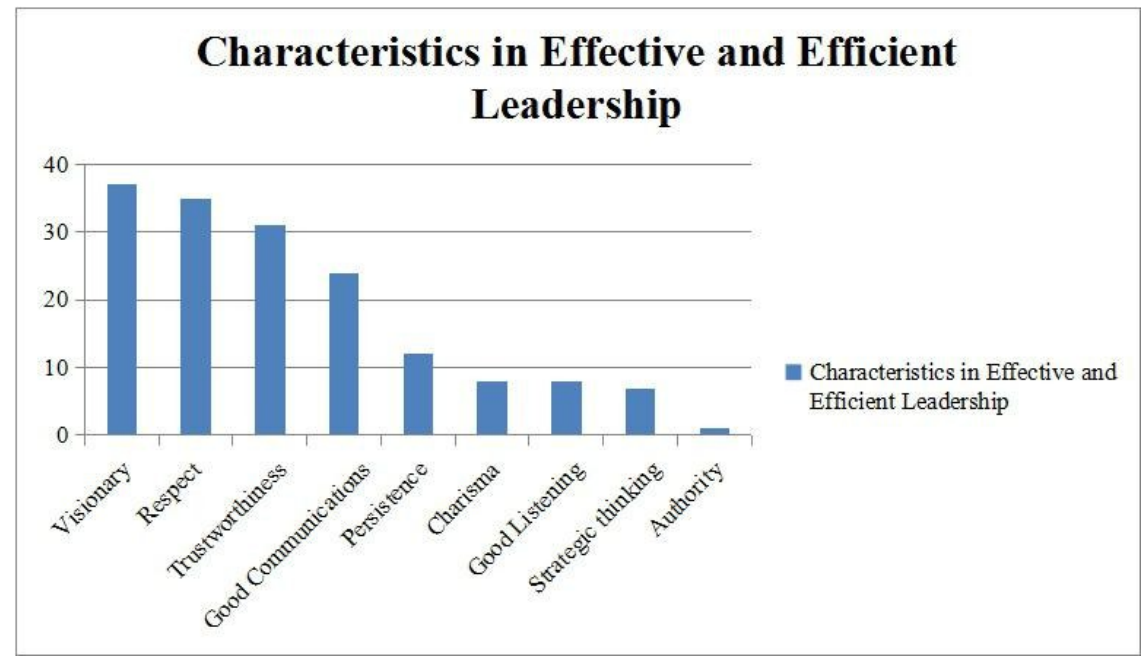


Figure 1: The Most Important Characteristic a Leader Needs to Shape Organizational Culture Effectively The CEO's Personality in Shaping Clan Culture Values and an Adaptive Environment

Clan culture emphasizes fostering human capital development. Adaptability is discussed in this paper section 2.1 and in terms of the CEO and the TMT's roles in shaping organizational cultures; this paper focuses on building a clan organizational culture defined by the long - term human resource development, team cohesion, and employee fulfillment with a high level of adaptability in the fastchanging business world. Emotional stability incorporated into the CEO' $\mathrm{s}$ adaptability is addressed in section 2.1, and in correlation with clan culture managing human capital, many studies have found that more emotionally stable leaders would tend to seek to create an organization with desired employee morale and relationships characterized by more cohesive team dynamics.

Regarding organizational characteristics linking to clan culture values, it is found that individuals with agreeable personality traits also held preferences for team - oriented and supportive corporate cultures (Judge and Cable, 1997). Take apple as an example. Unlike Steve Job's tradition and preference of eating with the design chief Jony Ive, the newly minted CEO Tim Cook reportedly tends to sit down at the Apple corporate cafeteria and actively interacts with various workers to understand their needs and expectations. By involving employees from different managerial levels and functional departments, CEOs could create a web of communications carrying organizational spirits and values deeply immersed into the organization. Such efforts in fostering team cohesion are far more than the leaders' solitary initiative in the business practices, thereby cultivating a sustainable organizational culture in an ongoing dialogue.

In shaping and maintaining a clan culture to fit in the changing economy, CEOs and supportive senior executives are recommended to maintain $\mathrm{e}^{-}$ motional stability and retain considerable adaptability in a way to be less prone to anxiety and experience fewer mood swings in the fast - changing business environment of ambiguity and uncertainty, interact more frequently with employees from different functional and managerial levels with agreeableness, empower them to emulate the role model set by CEO and better adapt to the changes, thereby fostering a clan culture with employee engagement and commitment.

\section{Conclusion and Recommendation}

The Covid - 19 pandemic is the most significant global crisis of this century, and this public health crisis threatens each of the 7.8 billion people. Each crisis is a seismic shock affecting organizational behaviors and testing the leadership in transforming business strategies and even forming a new culture of inclusiveness and openness to fit in. As noted and discussed in this paper, CEOs and the supportive TMTs are a powerful governance mechanism for monitoring a firm's strategic direction, developing the competitive business advantages for sustainable growth, initiating and coordinating the organizational change from inception to sustainment, and shaping the corporate culture which represents the shareholder values. Their behaviors and values not only influence the strategic managerial decisions but also consequentially affect the social environment where every employee affiliates. In a global environment with new landscapes driven by the cascading sense of vulnerability resulting from the Covid - 19 pandemic, CEOs are expected to be more adaptive to the continually reshuffling world of uncertainties. CEOs and senior executives serve as important business imperative embedded in every aspect of the organizational characteristics and sustainability. In conclusion, this paper recommends:

Organizations form a heterogeneous TMT composed of individuals with different functional backgrounds and competitive strengths. The diversity in leadership teams can better avoid groupthink and deal with complex and constantly changing environments to alter the strategic vision and move 
forward the business shift when necessary.

CEOs and senior executives possess a global mindset and demonstrate adaptability in managerial roles to fit in the fluctuating business environments and continuously carry on the employee motivation to foster greater team cohesion and human capital development to meet the evolving organizational requirement in the competitive landscape.

CEOs and senior executives should exhibit $\mathrm{e}^{-}$ motional stability and agreeableness charisma to foster a more relationship - oriented atmosphere of collaboration and team cohesion, thereby encouraging and evoking a clan culture with greater employee engagement and commitment.

CEOs and senior executives communicate the desired organizational culture by arranging corporate, departmental meetings and carrying out one - on - one communications. Provided that corporate culture is a social recognition formed by a network of interactions, formal and informal face- to - face communications are orchestrated and valued in shaping organizational culture.

CEOs and senior executives shall adopt effective Fin - Tech methods in upgrading the industry, analyzing and experimenting with the technology advancements and artificial intelligence platforms to promote the high - quality development of the business orientations in the waves of the digital economy and digital industrialization.

\section{References}

[1] Leslie Allan. (2012). Businessperform. com. Organization Change: Learning from the Best. [online]. Available from: http://www. businessperform. com/articles/change - management/organization _ change _ learning. html [Accessed August 2012]

[2] Michael A. Hitt, R. Duane Ireland \& Robert E. Hoskisson. (2006). Strategic Management: Competitiveness and Globalization. 7th edition. Kentucky, the US: South-western publishing.

[3] M. A. Hitt, B. W. Keats, \& E. Yucel, Strategic leadership in global business organizations, in W. H. Mobley \& P. W. Dorfman (eds. ). (2003). Advances in
Global Leadership, Oxford, the UK: Elsevier Science, Ltd. , 9-35.

[4] I. M. Levin, Vision revisited (2000). Journal of Applied Behavioral Science, 36: 91-107.

[5] Robert Moments. (2007). Top 7 Leadership Skills for Business Success. [online]. Available from: http:// top7business. com/? Top -7 - Leadership - Skills for-Business - Success \& id = 3632 [Accessed August 2012]

[6] Harvard Kennedy School. (2012). Ronald Heifetz on Leadership and Adaptability. [online ]. Available from: http://www. hks. harvard. edu/news - events/ publications/insight/management/ronald - heifetz [Accessed August 2012]

[7] Hart, S. L. , \& Quinn, R. E. (1993). Roles Executives play: CEOs, behavioral complexity, and firm performance. Human Relations, 46.

[8] Quinn, J. B. (1988). Beyond rational management: Mastering the paradoxes and competing demands of high performance. San Francisco: Jossey-Bass.

[9] Tara Duggan. (2012). Demand Media. What are the Core Competencies to Leadership Roles [online] Available from: http://smallbusiness. chron. com/core - competencies-leadership-roles-22419. html [ Accessed August 2012]

[10] Cindy Hardy. (2008). Understanding Corporate Culture. [online]. Available from: http://www. jobs. co. za/recruitment/recruitment - advice/article/94/ understanding - corporate- culture [Accessed August 2012]

[11] Judge, T. A. , \& Cable, D. M. (1997). Applicant personality, organizational culture, and organizational attraction. Personnel Psychology, 50, 359-393.

[12] Mindy L. Hall (2005) Shaping Organizational Culture: A Practitioner's Perspective. Peak Development Consulting, LLC. Volume 2, Issue 1.

[13] R. M. Fulmer \& M. Goldsmith. (2000). The Leadership Investment: Promoting Diversity in Leadership, New York: American Management Association.

[14] T. R. Giberso et al. (2009). Leadership and Organizational Culture: Linking CEO Characteristics to Cultural Values. Journal of Business \& Psychology, 24 : $123-137$ 